\title{
Purification and identification of five novel antioxidant peptides from goat milk casein hydrolysates
}

\author{
Z. Li, ${ }^{, 1}$ A. Jiang, † T. Yue, ${ }^{*}$ J. Wang, ${ }^{*}$ Y. Wang, ${ }^{*}$ and J. Su* \\ ${ }^{*}$ College of Food Science and Engineering, Northwest A\&F University, Yangling 712100, China \\ †College of Food Science, South China Agricultural University, Guangzhou 510642, China
}

\begin{abstract}
The present research described the preparation, purification, and identification of antioxidant peptides from goat milk casein (GMC). Goat milk casein was hydrolyzed by using a combination of neutral and alkaline proteases to obtain goat milk casein hydrolysates $(\mathrm{GMCH})$ with high antioxidant activity. After desalting by nonpolar macroporous absorption resin, $\mathrm{GMCH}$ was isolated and purified by gel filtration chromatography and reversed-phase HPLC, respectively, and further identified by nanoliter electrospray ionization-tandem mass spectrometry. Antioxidant activities of GMC, $\mathrm{GMCH}$, and pure peptides were evaluated and compared using free radical scavenging activity, metal ion chelating ability, and anti-lipid peroxidation ability. Compared with GMC, the free radical-scavenging ability and ferrous ion-chelating ability of GMCH increased significantly. The inhibition effect of lipid peroxidation of GMCH was much stronger than that of tertbutylhydroquinone and phytogermine and a little lower than that of ascorbic acid. The antioxidant activity of GMCH could be attributed to the high antioxidant activity of oligopeptides, especially 5 novel oligopeptides: Val-Tyr-Pro-Phe, Phe-Gly-Gly-Met-Ala-His, Phe-ProTyr-Cys-Ala-Pro, Tyr-Val-Pro-Glu-Pro-Phe, and TyrPro-Pro-Tyr-Glu-Thr-Tyr, which were first observed in GMCH. The antioxidant activity of these 5 novel oligopeptides and GMCH increased 3.59 to 380 times compared with GMC, combining anti-lipid peroxidation ability of GMCH, which indicated that GMCH and its purified fractions in different stages could be used as functional food ingredients, food additives, and pharmaceutical agents in the future.
\end{abstract}

Key words: goat milk casein hydrolysate (GMCH), antioxidant peptide, isolation and purification, identification

Received December 20, 2012

Accepted February 23, 2013.

${ }^{1}$ Corresponding author: lizhicheng@nwsuaf.edu.cn

\section{INTRODUCTION}

Chronic diseases and aging phenomena are relevant to the imbalance in free radical levels in the body. An excess of free radicals can cause lethal cellular effects by oxidizing membrane lipids, cellular proteins, DNA, and enzymes, thus shutting down cellular respiration (Urso and Clarkson, 2003). When the damage cannot be repaired promptly and accumulates to a certain extent, it often leads to diseases, such as atherosclerosis, diabetes, rheumatoid arthritis, and cancer (Halliwell, 2000; Abuja and Albertini, 2001; Collins, 2005; Hiller and Lorenzen, 2009). It is well known that lipid peroxidation occurring in food products causes rancid flavor, unacceptable taste, degradation in nutritive value, and shortening of shelf life in foods (Alférez et al., 2006; Kondyli et al., 2007). To prevent foods from undergoing deterioration and to provide protection against serious diseases, it is important to inhibit the peroxidation of lipids and the formation of free radicals occurring in the living body and foodstuffs. Lipid oxidation is inhibited by antioxidant agents.

Artificial antioxidants, such as butylated hydroxyanisole, butylated hydroxytoluene, and $n$-propyl gallate, exhibit strong antioxidant activity against several oxidation systems. However, the use of artificial antioxidants in foodstuffs is restricted or prohibited in some countries because of the potential risks for the living body. Antioxidants from natural sources are receiving increased attention. Food-derived peptides have been demonstrated to be the natural antioxidants without marked adverse effects. An increasing number of food protein hydrolysates and antioxidant peptides have been found to exhibit antioxidant activity (Chen et al., 1996; Li et al., 2007; Samaranayaka and Li-Chan, 2011), especially in bovine milk casein (Phelan et al., 2009; Pihlanto, 2006, Su et al., 2012). Suetsuna et al. (2000) identified an antioxidant peptide, Phe-Tyr-ProGlu-Leu, from bovine milk casein by ion exchange chromatography, gel filtration chromatography (GFC), and HPLC, and determined that Glu-Leu was the active center of the antioxidant peptide. Goat milk casein (GMC) differs greatly from bovine casein in content, peptide chain length, and AA sequences (Chen et al., 
1996; Hoelzl et al., 2005; Tomotake et al., 2006; Kondyli et al., 2007; Ceballos et al., 2009). Lee et al. (2005) obtained 3 angiotensin-converting enzyme inhibitory peptides from goat milk casein hydrolysates (GMCH). Although Sommerer et al. (2001) obtained 28 peptides composed of 3 to $8 \mathrm{AA}$ residues from the water-soluble extract of goat cheese, the functional characteristics of these peptides were not studied. Therefore, the objective of this study was to prepare and purify antioxidant peptides from GMC and further evaluate their in vitro antioxidant properties with different methods. Finally, the sequences of several peptides with higher antioxidant activity were determined by consecutive chromatography and tandem mass spectrometry.

\section{MATERIALS AND METHODS}

\section{Materials}

The composition of raw goat milk from Xinong Saanen dairy goats was $3.46 \%$ (wt/wt) milk fat, $2.72 \%$ (wt/wt) milk protein, and $4.41 \%$ (wt/wt) lactose. The contents of DM and nonfat milk solids in raw goat milk were $11.24 \%$ (wt/wt) and $7.79 \%$ (wt/wt), respectively.

The raw goat milk $(1,000 \mathrm{~mL})$ was first defatted by centrifugation at $2,500 \times g$ for $20 \mathrm{~min}$ at $4^{\circ} \mathrm{C}$. Then, the skimmed goat's milk was treated by isoelectric point precipitation. The precipitate was washed 2 times with $50 \mathrm{~m} M$ acetic acid-sodium acetate buffer at $\mathrm{pH} 4.4$, and centrifuged at $1,610 \times \mathrm{g}$ for $10 \mathrm{~min}$ at $4^{\circ} \mathrm{C}$ after each washing. The resultant precipitate was used as the wet GMC for further experiments. The protein content was $183.40 \mathrm{~g} / \mathrm{kg}$, determined by the method of Bradford (1976).

\section{Chemicals}

Four proteases, including neutral protease (EC 3.4.24.4), alkaline protease (EC 3.4.21.62), papain (EC 3.4.22.2), and trypsin (EC 3.4.21.4), were purchased from Amano Enzyme Co. (Nishiki, Nagoya, Japan). Acetonitrile and trifluoroacetic acid (TFA), both HPLC grade, were purchased from Fisher Co. (Fair Lawn, NJ) and Fluka Co. (Switzerland), respectively. Nonpolar macroporous absorption resin LS106 (specific surface area $\geq 950 \mathrm{~m}^{2} / \mathrm{g}$ ) was purchased from Xi'an LanShen Special Resin Co. (Xi'an, China); 2-deoxy-D-ribose, 2,2'-azinobis (3-ethylbenzothia-zoline-6- sulfonicacid; ABTS), 1,1-diphenyl-2-picrylhydrazyl (DPPH), phytogermine, tert-butylhydroquinone (TBHQ), and ferrozine were purchased from Sigma Co. (St. Louis, MO). Ultrapure water was obtained from a Merck Millipore water purification unit (Billerica, MA). Ascorbic acid, EDTA, and all other reagents were of analytical grade and obtained from commercial sources.

\section{Preparation of $\mathrm{GMCH}$}

Wet GMC $(65.43 \mathrm{~g})$ was dissolved in $10 \mathrm{~mL}$ of 0.1 $M \mathrm{NaOH}$ and diluted by addition of $150 \mathrm{~mL}$ of deionized water and hydrolyzed for $3 \mathrm{~h}$ with single proteases at their optimum hydrolysis conditions (Table 1) in a batch stirred tank reactor. For the compound protease, GMC was hydrolyzed first for $3 \mathrm{~h}$ under the optimum hydrolysis conditions of a single enzyme. Then, the complex was further hydrolyzed for $3 \mathrm{~h}$ under the optimum hydrolysis conditions of the other enzyme. The $\mathrm{pH}$ was kept at a stable value by adding $0.1 M \mathrm{NaOH}$ solution. After the hydrolysis was finished, GMCH was heated in boiling water for $10 \mathrm{~min}$ to inactivate the proteases to stop the reaction, cooled to room temperature, and centrifuged at $10,000 \times g$ at $4^{\circ} \mathrm{C}$ for $20 \mathrm{~min}$. The supernatant was lyophilized and stored at $-20^{\circ} \mathrm{C}$ until used.

\section{Determination of Antioxidant Activity and Relevant Parameters}

Hydroxyl Radical-Scavenging Activity. The scavenging effect of hydroxyl radical was assayed by using the 2-deoxy-D-ribose oxidation method of Halliwell et al. (1987), Chung et al. (1997), and Zhu et al. (2006), with minor modifications. The reagents were added into a reaction tube in the following order: $0.2 \mathrm{~mL}$ of sample solution at various concentrations, $0.9 \mathrm{~mL}$ of $0.1 \mathrm{M} \mathrm{KH}_{2} \mathrm{PO}_{4}-\mathrm{KOH}$ buffer ( $\mathrm{pH} 7.4$ ), and $0.2 \mathrm{~mL}$ of 10 $\mathrm{m} M \mathrm{FeSO}_{4}$-EDTA, $0.5 \mathrm{~mL}$ of $10 \mathrm{~m} M$ 2-deoxy-D-ribose, and $0.2 \mathrm{~mL}$ of $10 \mathrm{mM} \mathrm{H}_{2} \mathrm{O}_{2}$. Solutions of $\mathrm{FeSO}_{4}$-EDTA and $\mathrm{H}_{2} \mathrm{O}_{2}$ were prepared just before use. The reaction solution was incubated at $37^{\circ} \mathrm{C}$ for $1 \mathrm{~h}$. Then, $1 \mathrm{~mL}$ of

Table 1. The optimum enzyme hydrolysis conditions of different proteases for goat milk casein

\begin{tabular}{lcccr}
\hline Parameter & $\begin{array}{c}\text { Neutral } \\
\text { protease }\end{array}$ & $\begin{array}{l}\text { Alkaline } \\
\text { protease }\end{array}$ & Papain & Trypsin \\
\hline pH & 7.5 & 8.5 & 6.5 & 7.5 \\
Temperature $\left({ }^{\circ} \mathrm{C}\right)$ & 50 & 45 & 60 & 50 \\
Addition of enzyme $(\mathrm{U} / \mathrm{g}$ of protein) & 4,000 & 300 & 4,000 & 2,500 \\
Substrate concentration $(\mathrm{g} / \mathrm{kg})$ & 60 & 60 & 60 & 60 \\
\hline
\end{tabular}


$2.8 \%$ (wt/wt) TCA was added to stop the reaction. The color was developed by adding $1 \mathrm{~mL}$ of $0.5 \%$ (wt/ vol) $\beta$-thiobarbituric acid into reaction tubes that were placed into a boiling water bath for $15 \mathrm{~min}$. The tubes were cooled under running water and the absorbance measured at $532 \mathrm{~nm}$. Analyses of all samples were run in triplicate and averaged. The results were calculated as the percentage of hydroxyl radical-scavenging effect according to formula [1]:

$$
\begin{gathered}
\text { Hydroxyl scavenging effect }(\%)= \\
{[(\mathrm{Ac}-\mathrm{As}) / \mathrm{Ac}] \times 100,}
\end{gathered}
$$

where Ac and As were the absorbance of the control and sample, respectively.

DPPH Radical-Scavenging Activity. The scavenging effect of DPPH radical was estimated according to the methods of Thiansilakul et al. (2007) and Mao et al. (2011), with some modifications. In brief, $1.5 \mathrm{~mL}$ of sample was added to $1.5 \mathrm{~mL}$ of $\mathrm{DPPH}$ radical solution $(0.2 \mathrm{~m} M)$ prepared freshly in ethanol. After thorough mixing, the solutions were kept at room temperature for $30 \mathrm{~min}$ in the dark and ascorbic acid was used for comparison. The absorbance of the samples was monitored at $517 \mathrm{~nm}$. Background interferences from absolute ethanol and water were deducted from the activities before calculating radical-scavenging activity. The DPPH radical-scavenging ability was calculated in the same way as for hydroxyl.

ABTS Radical-Scavenging Activity. The ABTS radical-scavenging assay was conducted according to the methods of Aewsiri et al. (2009) and Hiller and Lorenzen (2009), with some modifications, and was comparable to DPPH radical-scavenging activity. The ABTS radical (ABTS•) was generated by reacting 7.4 $\mathrm{m} M$ ABTS and potassium persulfate $(2.6 \mathrm{mM})$ at a ratio of $1: 1(\mathrm{vol} / \mathrm{vol})$ and incubating at room temperature in the dark for 12 to $16 \mathrm{~h}$. The ABTS• solution was diluted by mixing $1 \mathrm{~mL}$ of ABTS• solution with $20 \mathrm{~mL}$ (1:20) of ethanol to obtain an absorbance of 0.7 \pm 0.02 units at $734 \mathrm{~nm}$. To $1 \mathrm{~mL}$ of sample or ethanol (the control), $2 \mathrm{~mL}$ of ABTS• solution was added and mixed thoroughly, and incubated for $6 \mathrm{~min}$ at room temperature, and the absorbance was measured at 734 $\mathrm{nm}$. Analyses of all samples were run in triplicate and averaged. The ABTS quenching effect was calculated in the same way as for hydroxyl and DPPH.

Metal Ion-Chelating Activity. The ability to chelate metal ions was determined by the methods of Wang et al. (2008) and Xie et al. (2008) with minor modifications. In brief, $1 \mathrm{~mL}$ of sample solution and $50 \mu \mathrm{L}$ of $2 \mathrm{mM} \mathrm{FeCl}_{2} \cdot 4 \mathrm{H}_{2} \mathrm{O}$ were added to $1.85 \mathrm{~mL}$ of deionized water, and the mixture was stored at room temperature for $30 \mathrm{~s}$. Then, $0.1 \mathrm{~mL}$ of $5 \mathrm{~m} M$ ferrozine was added to the reaction mixture and mixed, and absorbance at $562 \mathrm{~nm}$ was determined against a blank after 10 min resting time at room temperature. The chelating effects were expressed as the half-maximal inhibitory concentration $\left(\mathbf{I C}_{50}\right)$.

Inhibition of Linoleic Acid Autoxidation. The inhibition effect on lipid peroxidation of GMCH with different periods of incubation was measured in a linoleic acid model system according to the methods of Zhu et al. (2006) and Li et al. (2007), with some modifications. Briefly, $2.0 \mathrm{~mL}$ of the test sample $(0.3$, 2.0 , and $6.0 \mathrm{~m} M, \mathrm{pH} 7.0$ ) was added in a glass test tube that included $1.5 \mathrm{~mL}$ of $0.1 \mathrm{M}$ sodium phosphate buffer $(\mathrm{pH} 7.0)$ and $1.5 \mathrm{~mL}$ of $50 \mathrm{~m} M$ linoleic acid in ethanol (99.5\%). The mixed solution in a lightly sealed screw-cap glass tube was incubated in the dark at $60^{\circ} \mathrm{C}$. The degree of linoleic acid oxidation was measured at 24-h intervals using the ferric thiocyanate method. In brief, $100 \mu \mathrm{L}$ of the reaction mixture was mixed with $75 \%$ ethanol $(4.5 \mathrm{~mL})$ followed by the addition of 100 $\mu \mathrm{L}$ of $30 \%$ ammonium thiocyanate, $200 \mu \mathrm{L}$ of $1.0 \mathrm{M}$ $\mathrm{HCl}$, and $100 \mu \mathrm{L}$ of $20 \mathrm{mM}$ ferrous chloride solution in $3.5 \% \mathrm{HCl}$. The reaction solution was $5 \mathrm{~mL}$ in total. After a 5-min incubation, the color development of the solution, which represents the linoleic acid oxidation, was measured at $500 \mathrm{~nm}$. Ascorbic acid $(2.0 \mathrm{mM})$, TBHQ $(2.0 \mathrm{~m} M)$, and phytogermine $(2.0 \mathrm{~m} M)$ were used instead of the test sample as positive controls, and $0.1 M$ sodium phosphate buffer ( $\mathrm{pH} 7.0)$ was used as a negative control.

Determination of $\boldsymbol{I C}_{50}$ Value. The $\mathrm{IC}_{50}$ value is the sample concentration required for $50 \%$ inhibition in vitro. Measurement of the $\mathrm{IC}_{50}$ value of hydroxyl radical-scavenging activity (for example) was as follows. A sample was diluted to the original sample concentration of $1 / 2,1 / 4,1 / 8,1 / 16,1 / 32,1 / 64,1 / 128$, and so on, with deionized water until at least one of the effect values was greater than $50 \%$ of the total effect value. The hydroxyl radical-scavenging activities of spiked samples were determined, and then the $\mathrm{IC}_{50}$ values of hydroxyl radical-scavenging activity were calculated by using Northwest $\mathrm{A} \& \mathrm{~F}$ University $\mathrm{IC}_{50}\left(\mathrm{EC}_{50}\right)$ calculation software, version 6.55 .

Measurement of $\mathrm{NaCl} \mathrm{Concentration.} \mathrm{Determi-}$ nation of $\mathrm{NaCl}$ concentration was as follows. The electrical conductivities of $0.1,1.0,5.0,10.0$, and $100.0 \mathrm{mM}$ $\mathrm{NaCl}$ solutions were determined with electrical conductivity meter (DDS307, Shanghai Yizhu Electronic Co. Ltd., Shanghai, China). The standard curve between $\mathrm{NaCl}$ concentration and its electrical conductivity was obtained. The $\mathrm{NaCl}$ concentrations in GMCH and the effluent were calculated according to the equation $y=$ $101.81 x+18.785\left(R^{2}=0.99\right)$, where $y$ was the electri- 
cal conductivity $(\mu \mathrm{S} / \mathrm{cm})$ and $x$ was the concentration of $\mathrm{NaCl}(\mathrm{m} M)$.

\section{Desalting of $\mathrm{GMCH}$}

The GMCH was desalted with self-packed column (LS106, nonpolar macroporous adsorption resin, LanShen Special Resin Co.). The column (balanced adsorption capacity was $10.68 \mathrm{mg} / \mathrm{mL}$ ) was first equilibrated with deionized water until the electrical conductivity of the effluent was equivalent to that of the deionized water. Then, GMCH $(11.5 \mathrm{mg} / \mathrm{mL})$ was introduced into the column and eluted with deionized water and $75 \%$ ( $\mathrm{vol} / \mathrm{vol}$ ) ethanol at a flow rate of $2.0 \mathrm{~mL} / \mathrm{min}$ at room temperature. The effluent fractions eluted with $75 \%$ (vol/vol) ethanol at $220 \mathrm{~nm}$ were collected, vacuumconcentrated, and freeze-dried.

\section{Isolation and Purification of GMCH}

The desalted GMCH was dissolved in ultrapure water and isolated by a Superdex Peptide 10/300GL column $(10 \times 300 \mathrm{~mm}$, Amersham Co., Uppsala, Sweden) that had been equilibrated with ultrapure water. The peptide fraction was eluted with ultrapure water at $0.5 \mathrm{~mL} / \mathrm{min}$ at room temperature, and the eluted fractions at a wavelength of $254 \mathrm{~nm}$ were collected. The isolated peptides were lyophilized for the analysis of the antioxidant activities and used for further purification by reversed-phase HPLC (RP-HPLC).

The fractions obtained by GFC were further isolated by a semi-preparative RP-HPLC (LC-8A, Shimadzu, Tokyo, Japan) on a Shim-pack PRC-ODS column $(20 \times$ $250 \mathrm{~mm}$, Shimadzu). Here, the column was equilibrated with $0.1 \%$ (vol/vol) TFA in water (solvent A), and a linear gradient was developed by using solvent $\mathrm{A}$ and solvent B $[0.1 \%$ (vol/vol) TFA in $80 \%$ (vol $/ \mathrm{vol}$ ) acetonitrile in deionized water]. The effluent was achieved with a linear gradient from solvent A to $70 \%$ (vol/vol) solvent $\mathrm{B}$ for $40 \mathrm{~min}$ at a flow rate of $2.0 \mathrm{~mL} / \mathrm{min}$, and the eluted peaks were detected by UV absorbance at $215 \mathrm{~nm}$. Each of the peptides was manually collected and then evaporated to dryness under vacuum (Guo et al., 2009). The antioxidant activities of the purified peptides were determined.

\section{Structural Identification of Antioxidant Peptides}

The desirable antioxidant peptide fractions after RPHPLC purification were directed into the mass spectrometer (Q-TOF2, Micromass Co., Manchester, UK), which were operated in the positive nano-electrospray ionization (ESI) mode. The drying and ESI nebulizing gas was high-purity nitrogen. Spectra were recorded over a mass/charge $(\mathrm{m} / \mathrm{z}$ ) range from 50 to 1,800 (Ren et al., 2008). The peptide sequences were deducted by processing the tandem MS (MS/MS) spectra using MaxEnt3 and MasSeq (Micromass Co.) as well as manual calculation.

\section{Statistical Analysis}

The statistical analysis was carried out by using SPSS 17.0 (SPSS Inc., Chicago, IL) and DPS 7.55 (Tang Q., Hangzhou, China) software. The data were expressed as mean \pm standard deviations, and the mean values were compared by the Duncan's new multiple range test at 5 or $1 \%$ probability.

\section{RESULTS AND DISCUSSION}

\section{Antioxidant Activity of GMCH}

The GMCH had strong scavenging ability for hydroxyl and DPPH radicals (Figure 1). The type of protease used greatly affected the antioxidant activity of GMCH. Generally, the free radical-scavenging ability of GMCH hydrolyzed by compound proteases was higher than that hydrolyzed by a single protease. The $\mathrm{IC}_{50}$ value of scavenging hydroxyl radical and $\mathrm{DPPH}$ radical of GMCH by the compound protease consisting of neutral protease and alkaline protease was lowest of all compound proteases; thus, the antioxidant activity of the GMCH by a combination of neutral protease and alkaline protease was highest. Therefore, the compound protease (neutral protease and alkaline protease) was selected to hydrolyze GMC. The optimum enzymolysis conditions of GMC were as follows: hydrolysis for 24 $\mathrm{h}$ at $50^{\circ} \mathrm{C}, \mathrm{pH} 7.5$, with a substrate concentration of $60 \mathrm{~g} / \mathrm{kg}$; the enzyme dosages of neutral and alkaline proteases were 4,000 and $250 \mathrm{U} / \mathrm{g}$, respectively, using uniform experiments and validation experiments (process not shown).

For the same substrate, the antioxidant activity of hydrolysates depends on the type of enzyme because specific peptide bonds are hydrolyzed by specific proteases. Generally, alkaline protease mainly hydrolyzes the carboxy terminus of hydrophobic AA residues of Val, Pro, Gly, Ala, and Phe, whereas neutral protease hydrolyzes the amino terminus of Leu, Phe, and other AA. Peptides consisting of Met, Glu, Tyr, Lys, His, Cys, Val, and Pro possess strong antioxidant activity (Chen et al., 1998; Rajapakse et al., 2005). A large amount of antioxidant peptides from GMC might have been produced after hydrolysis by a combination of neutral protease and alkaline protease, which make GMCH exhibit strong antioxidant activity. 


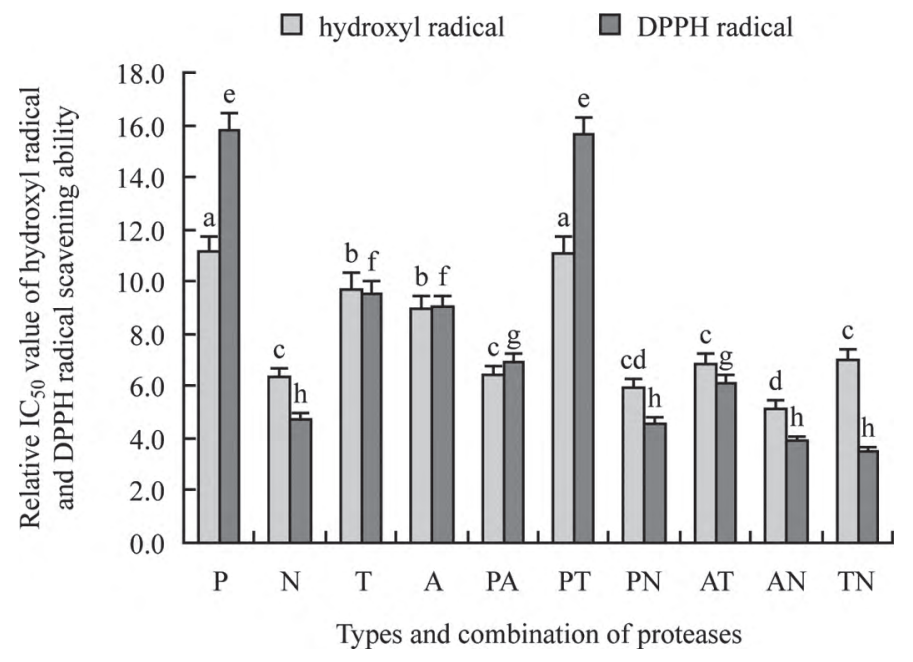

Figure 1. Effect of types and combinations of protease on relative scavenging activity of hydroxyl and 1,1-diphenyl-2-picrylhydrazyl $(\mathrm{DPPH})$ radicals for goat milk casein hydrolysates (GMCH). Different lowercase letters indicate significant differences at $P<0.05$ between the groups of hydroxyl radicals $(\mathrm{a}-\mathrm{d})$ and groups of $\mathrm{DPPH}$ radicals $(\mathrm{e}-\mathrm{h}) \cdot \mathrm{IC}_{50}=$ half-maximal inhibitory concentration in vitro; $\mathrm{P}=\mathrm{pa}$ pain; $\mathrm{N}=$ neutral protease; $\mathrm{T}=$ trypsin; $\mathrm{A}=$ alkaline protease; $\mathrm{PA}$, PT, PN, AT, AN, TN = combinations of different proteases.

Compared with GMC, the hydroxyl radical-scavenging ability of $\mathrm{GMCH}$ increased 3.59-fold ( $\mathrm{IC}_{50}$ value decreased 3.59-fold) and the corresponding $\mathrm{IC}_{50}$ value of the positive control (ascorbic acid) could not be obtained (Table 2), indicating that the hydroxyl radical-scavenging capacity of ascorbic acid was very low by the method of 2-deoxy-D-ribose oxidation. The ABTS radical-scavenging ability of GMCH increased 158.72 -fold $\left(\mathrm{IC}_{50}\right.$ value reduced 158.72 -fold), which was 8 times higher than the positive control (ascorbic acid). Although the $\mathrm{IC}_{50}$ value of scavenging $\mathrm{DPPH}$ radical of GMCH $(244.275 \pm 11.535 \mu \mathrm{g} / \mathrm{mL})$ was much higher than that of ascorbic acid $(6.033 \pm 0.229 \mu \mathrm{g} / \mathrm{mL} ; P$ $<0.01)$, compared with that of GMC $\left(\mathrm{IC}_{50}\right.$ could not be obtained, Table 2), the DPPH radical-scavenging ability of GMCH markedly increased $(P<0.01)$. These results showed that free radical scavenging ability of
GMCH increased significantly after hydrolysis. The $\mathrm{IC}_{50}$ value of chelating ferrous ions of GMCH (48.184 $\pm 3.95 \mu \mathrm{g} / \mathrm{mL}$ ) was much higher than that of EDTA $(10.056 \pm 0.749 \mu \mathrm{g} / \mathrm{mL} ; P<0.01)$, which was much lower than that of GMC $(262.174 \pm 13.252 \mu \mathrm{g} / \mathrm{mL} ; P$ $<0.01)$. This indicated that the ability of GMCH to chelate ferrous ions was increased 5.44 times over that of GMC.

The antioxidant activity of a substance can be identified more accurately by assessing scavenging activities on free radicals generated in oxidative systems. Therefore, hydrolysates were tested for their scavenging effects on hydroxyl, DPPH, and ABTS radicals. Among the oxygen radicals, the chemical activity of hydroxyl radical is the strongest and hydroxyl radical reacts easily with almost all the substances in the cell and induces severe damage to cells (Je et al., 2007). Therefore, removal of the hydroxyl radical is probably one of the most effective defenses of a living body against various diseases. The hydroxyl radical is also effective in initiating lipid peroxidation reactions. Determination of hydroxyl radical-scavenging activity provides useful information on antioxidant activities (Xie et al., 2008; Kang et al., 2011). The high hydroxyl radicalscavenging activity shown by GMCH strengthens its antioxidant activity and the ability to protect hydroxyl radical-induced damage. Ascorbic acid as a positive control was also tested for free radical-scavenging effects. Interestingly, the $\mathrm{IC}_{50}$ value of ascorbic acid on scavenging hydroxyl radical could not be obtained for any concentration of ascorbic acid by the 2-deoxy-Dribose oxidation method; this finding needs to be further investigated.

The DPPH and ABTS radicals are both stable free radicals and they can accept electrons or hydrogen radicals to become stable diamagnetic molecules. Therefore, DPPH and ABTS are commonly used as substrates to evaluate the antioxidant activity of an antioxidant. We changed the methods for determining ABTS radicalscavenging activity in accordance with the method of $\mathrm{DPPH}$ radical in order to compare the methods. As

Table 2. Half-maximal inhibitory concentration $\left(\mathrm{IC}_{50}\right)$ value of antioxidant activity of goat milk casein (GMC) and goat milk casein hydrolysates $(\mathrm{GMCH})$

\begin{tabular}{|c|c|c|c|c|}
\hline \multirow[b]{2}{*}{ Item } & \multicolumn{3}{|c|}{ Scavenging ability ${ }^{1}(\mu \mathrm{g} / \mathrm{mL})$} & \multirow{2}{*}{$\begin{array}{l}\text { Chelating effect of } \\
\text { ferrous ions }(\mu \mathrm{g} / \mathrm{mL})\end{array}$} \\
\hline & Hydroxyl radical & DPPH radical & ABTS radical & \\
\hline $\begin{array}{l}\text { GMC } \\
\text { GMCH } \\
\text { Ascorbic acid }\end{array}$ & $\begin{aligned} 292.008 & \pm 12.169^{\mathrm{a}} \\
81.400 & \pm 2.462^{\mathrm{b}} \\
& -\end{aligned}$ & $\begin{aligned} & -^{2} \\
244.275 & \pm 11.535^{\mathrm{a}} \\
6.033 & \pm 0.229^{\mathrm{b}}\end{aligned}$ & $\begin{aligned} 71.251 & \pm 2.747^{\mathrm{a}} \\
0.449 & \pm 0.027^{\mathrm{b}} \\
4.947 & \pm 0.183^{\mathrm{c}}\end{aligned}$ & $\begin{aligned} 262.174 & \pm 13.252^{\mathrm{a}} \\
48.184 & \pm 3.95^{\mathrm{b}} \\
10.056 & \pm 0.749^{\mathrm{c}, 3}\end{aligned}$ \\
\hline
\end{tabular}



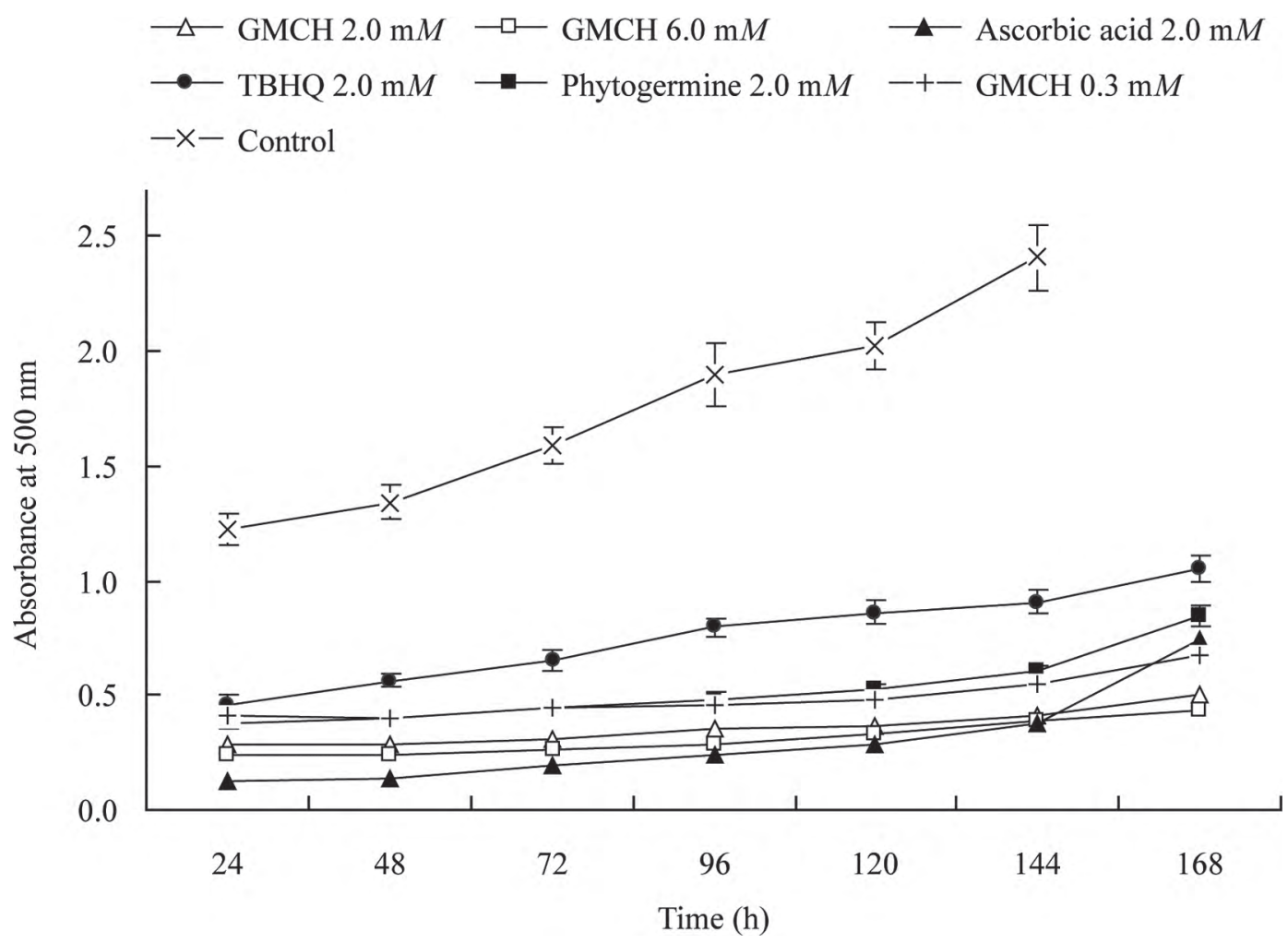

Figure 2. The inhibition effect of goat milk casein hydrolysates $(\mathrm{GMCH})$ on lipid peroxidation in a linoleic acid model system. TBHQ $=$ tert-butylhydroquinone.

shown in Table 2, GMCH greatly quenched the hydroxyl, DPPH, and ABTS radicals, indicating that GMCH is a good antioxidant compound with strong free radical scavenging activity compared with GMC. One possible reason is that some peptides of GMCH are electron donors, which could react with free radicals, convert them to more stable products, and terminate the radical chain reaction.

As shown in Table 2, the method for determining the radical-scavenging activity of ABTS was more sensitive than that for DPPH radical. In addition to the different solubility, the DPPH radical cannot react with aromatic acid with one hydroxyl, or with flavonoid without a hydroxyl in the $\beta$-ring, whereas ABTS radical can react with any hydroxylated aromatic compound (Yokozawa et al., 1998; Nanjo et al., 1999). Therefore, the $\mathrm{IC}_{50}$ value of GMCH on scavenging ABTS radical was lower than that of DPPH radical.

In addition to free radical-scavenging ability, the ability of GMCH to chelate metal ions was also determined. It is well known that transition metal ions are involved in many oxidation reactions in vivo. Ferrous ions $\left(\mathrm{Fe}^{2+}\right)$ can catalyze the Haber-Weiss reaction and induce superoxide anion to form more hazardous hydroxyl radicals. Hydroxyl radicals react rapidly with the adjacent biomolecules and induce severe damage. It has been reported that the scavenging of hydroxyl radical by antioxidant is effective mainly via chelation of metal ions. Because compounds interfering with the catalytic activity of metal ions could affect the peroxidative process, the measurement of chelating ability is important in the evaluation of free radical-scavenging activity of the compound (Halliwell and Gutteridge, 1990; Xie et al., 2008). The stronger the metal chelating ability, the stronger the antioxidant activity of the antioxidant. In this study, GMCH exhibited much stronger metal chelating activity than did GMC $(P<0.01)$, although it was significantly lower than that of EDTA, which had the strongest metal chelating capacity. Metal chelating ability may be involved in antioxidant activity and it affects other functions that contribute to the antioxidant activity. Accordingly, it is suggested that the chelating effect of GMCH to ferrous ions would be somewhat beneficial to exert protection against oxidative damage, which might be the mechanism of the free radical scavenging of GMCH.

Goat milk casein, GMCH, and ascorbic acid differed greatly in scavenging ability on different free radicals (Table 2), which showed that the methods for determination of free radical-scavenging ability, including 


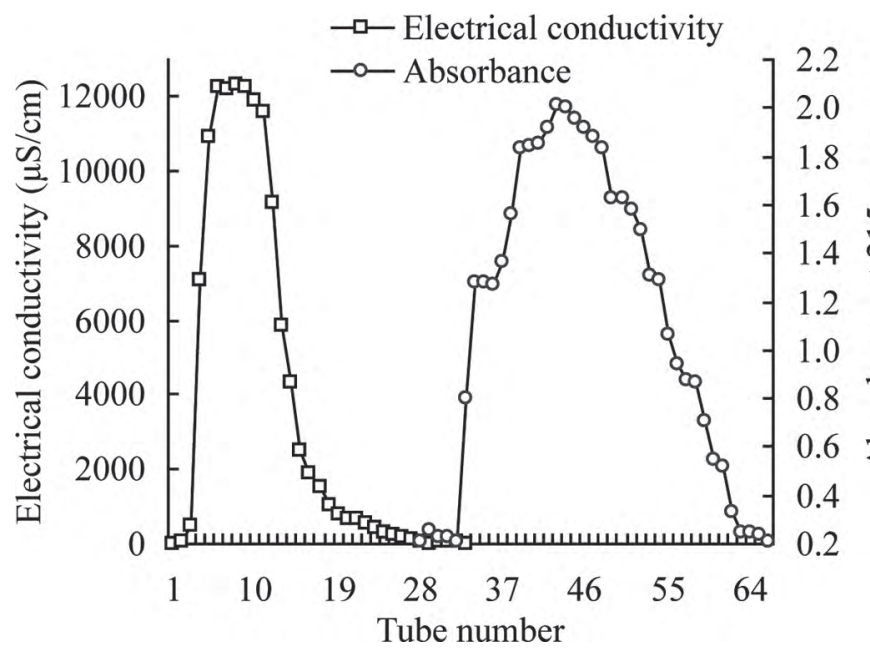

Figure 3. The relationship between electrical conductivity and absorbance of goat milk casein hydrolysates during the desalting process.

hydroxyl radical, DPPH radical, superoxide anion radical (data not shown), and ABTS radical, could not be replaced by one another. The scavenging capacity of one substance against one type of free radical could not be used to infer its ability against other free radicals because the principles and methods for the determination of different free radicals scavenging ability differ.

The greater the absorbance at $500 \mathrm{~nm}$, the higher the peroxidation level becomes in the linoleic acid system. The absorbance of GMCH in the linoleic acid system was much less than that of the negative control and less than or equal to that of the positive controls TBHQ and phytogermine (the absorbance at $500 \mathrm{~nm}$ of only 0.3 $\mathrm{m} M$ GMCH and $2.0 \mathrm{~m} M$ phytogermine was very close), and was greater than the positive control ascorbic acid (Figure 2). Figure 2 indicates that GMCH could inhibit linoleic acid peroxidation and was dose-dependent $(0.3$ $\mathrm{m} M \rightarrow 6 \mathrm{~m} M)$. The inhibition effect of lipid peroxidation of GMCH was stronger than that of the same concentration of TBHQ and phytogermine and weaker than that of ascorbic acid in linoleic acid model system. But the stability of antilipid peroxidation ability of $\mathrm{GMCH}$ was greater than that of ascorbic acid after incubation for $168 \mathrm{~h}$. This showed that GMCH could be used as a natural antioxidant in the food industry and pharmaceutical industry. This is promising for large-scale production because no purification steps are required, which means $\mathrm{GMCH}$ has a great potential application in food production.

\section{Desalting of $\mathrm{GMCH}$}

The salt peaks and GMCH peaks could not be isolated using the desalting column (5-mL Hitrap, Amersham Co.) because the molecular weight of salt
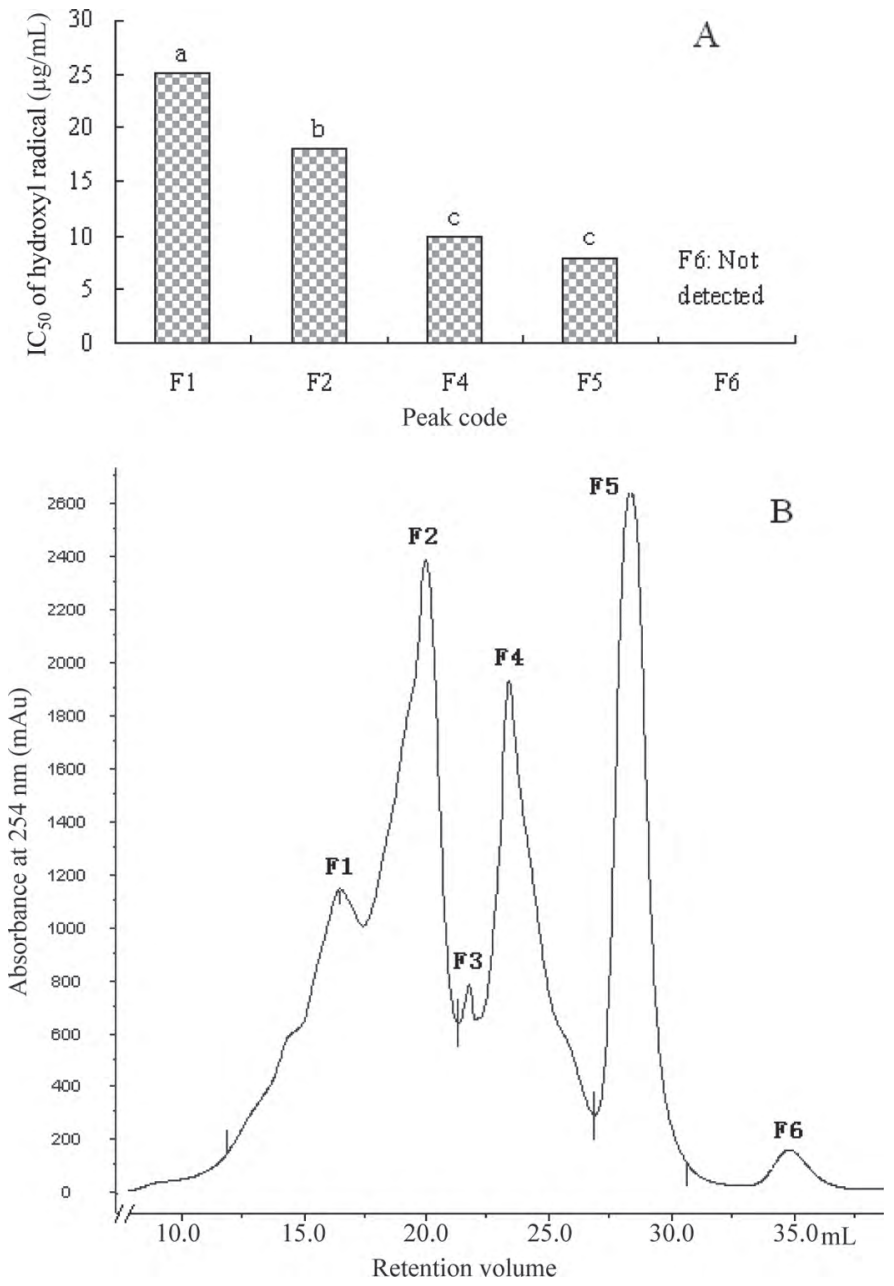

Figure 4. The gel filtration chromatography profiles of goat milk casein hydrolysates and antioxidant activity of fractions (F1 to F6). ${ }^{\mathrm{a}-\mathrm{c}}$ Bars with different letters differ $(P<0.01) . \mathrm{IC}_{50}=$ half-maximal inhibitory concentration in vitro; $\mathrm{mAU}=$ milli arbitrary units.

(mainly $\mathrm{NaCl}$ ) was very close to that of the components in GMCH. Therefore, the electrical conductivities of solutions were measured because the concentrations of $\mathrm{NaCl}$ were proportional to the electrical conductivities of solutions at a certain temperature. The concentration of $\mathrm{NaCl}$ in $\mathrm{GMCH}$ was obtained through a standard curve of electrical conductivity and concentration of $\mathrm{NaCl}$.

The electrical conductivity of GMCH could be decreased from 12,000 to $26.2 \pm 2.88 \mu \mathrm{S} / \mathrm{cm}$ at $20^{\circ} \mathrm{C}$ (Figure 3) with nonpolar macroporous resin (LS106). The electrical conductivity of $26.2 \mu \mathrm{S} / \mathrm{cm}$ was equivalent to that of $0.10 \mathrm{mM} \mathrm{NaCl}$ and fully met the requirements of the ESI mass spectrometer that the salt concentration of samples is not more than $1.0 \mathrm{mM}$ (Siuzdak, 1994). Therefore, the desalting effect of the self-packed column (wide surface nonpolar macroporous absorption resin) was much better than the desalting column. 
Table 3. Half-maximal inhibitory concentration $\left(\mathrm{IC}_{50}\right)$ values for eliminating the hydroxyl radical and the increase in multiples of fractions from goat milk casein hydrolysates (GMCH)

\begin{tabular}{|c|c|c|c|c|}
\hline Source & Fraction & $\begin{array}{l}\mathrm{IC}_{50} \text { value } \\
(\mu \mathrm{g} / \mathrm{mL})\end{array}$ & $\begin{array}{l}\mathrm{IC}_{50} \text { value of } \mathrm{GMCH} / \\
\mathrm{IC}_{50} \text { value of fractions }\end{array}$ & $\begin{array}{c}\mathrm{IC}_{50} \text { value of goat milk } \\
\text { casein }(\mathrm{GMC}) / \mathrm{IC}_{50} \text { value } \\
\text { of fractions }\end{array}$ \\
\hline Gel filtration & F4 & $9.968 \pm 0.453$ & 8.166 & 29.295 \\
\hline chromatography $^{5}$ & F5 & $7.924 \pm 0.332$ & 10.273 & 36.851 \\
\hline \multirow[t]{5}{*}{ HPLC } & F4-3 & $0.8260 \pm 0.019$ & 98.547 & 353.521 \\
\hline & F4-5-1 & $0.980 \pm 0.023$ & 83.061 & 297.967 \\
\hline & F4-5-2 & $0.801 \pm 0.021$ & 101.623 & 364.554 \\
\hline & F5-2 & $0.775 \pm 0.016$ & 107.815 & 376.785 \\
\hline & F5-4 & $0.791 \pm 0.022$ & 104.225 & 369.163 \\
\hline
\end{tabular}

${ }^{1}$ The $\mathrm{IC}_{50}$ values for eliminating the hydroxyl radical of GMC and GMCH were 292.008 \pm 12.169 and 81.400 $\pm 2.462 \mu \mathrm{g} / \mathrm{mL}$, respectively.

\section{Isolation and Purification of GMCH and Antioxidant Activity of Fractions}

Six fractions were isolated from GMCH by GFC at $254 \mathrm{~nm}$. The contents of the main fractions distributed on peaks F1, F2, F4, and F5 (Figure 4A) accounted for $16.73,31.56,27.12$, and $23.16 \%$ of the total peak area, respectively. Lower $\mathrm{IC}_{50}$ values of hydroxyl radical scavenging activity of F4 and F5 indicated that these fractions had higher antioxidant activity (Figure 4B); therefore, the next isolation and purification mainly focused on fractions F4 and F5.

Six main sub-fractions, F4-1 to F4-6, resulted from further isolation of fraction F4 by RP-HPLC, and the peaks F4-3 and F4-5 accounted for higher relative content of the total peak area of fraction F4 and were valuable to collect (Figure 5). Two peptide fractions, F4-5-1 and F4-5-2, were obtained after purification of F4-5 and 2 peptide fractions F5-2 and F5-4 purified from fraction F5 had higher antioxidant activity. After further purification by a semi-preparative RP-HPLC at a flow rate of $1.0 \mathrm{~mL} / \mathrm{min}$, the purity index of these peptide fractions (F4-3, F4-5-1, F4-5-2, F5-2, and F5-4) detected through analytical RP-HPLC $(4.6 \times 250 \mathrm{~mm}$ Shimpack C18, Shimadzu) reached 0.9999, indicating that these were pure, single-component antioxidant peptides by GFC and RP-HPLC. Fractions F4-3, F4-51, F4-5-2, F5-2, and F5-4 accounted for 0.23, 2.34, 2.50, 1.18 , and $1.97 \%$ of the original total peak area (Figure 4B), respectively.

The $\mathrm{IC}_{50}$ values of hydroxyl radical scavengingactivity of GMCH were 3.59 times higher compared with GMC. The antioxidant activity of the fractions was stronger following purification of GMCH. The hydroxyl radical scavenging-ability of the main fractions increased 8 to 110 times compared with that of $\mathrm{GMCH}$ and increased to 29 to 380 times that of GMC (Table 3). Thus, GMCH and its isolated fractions in different stages could be applied to functional food ingredient, food additives, and pharmaceutical agents in the future.

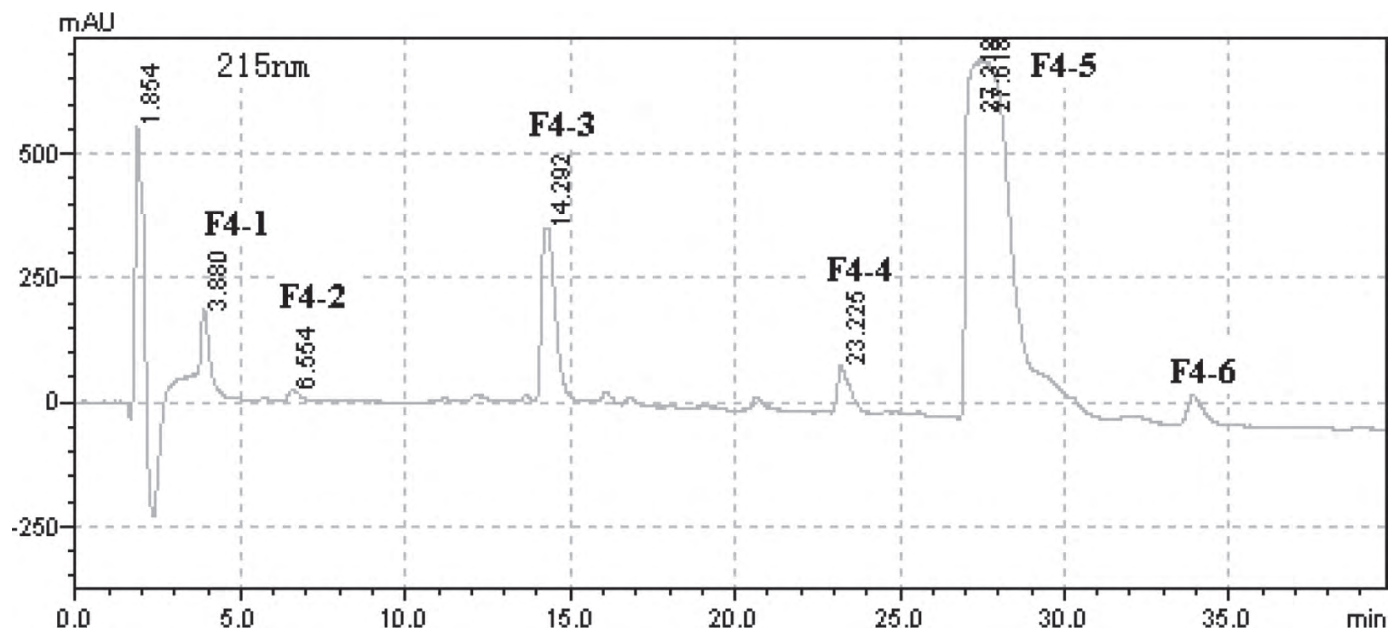

Figure 5. Reversed phase-HPLC profile of fraction F4 from goat milk casein hydrolysates. mAU = milli arbitrary units. 
Table 4. Structural identification of antioxidant peptides from goat milk casein hydrolysates

\begin{tabular}{lll}
\hline Fraction & $\begin{array}{c}\text { Molecular } \\
\text { weight }\end{array}$ & AA sequence \\
\hline F4-3 & 524.28 & VYPF (Val-Tyr-Pro-Phe) \\
F4-5-1 & 696.30 & FPYCAP (Phe-Pro-Tyr-Cys-Ala-Pro) \\
F4-5-2 & 618.32 & FGGMAH (Phe-Gly-Gly-Met-Ala-His) \\
F5-2 & 931.47 & YPPYETY (Tyr-Pro-Pro-Tyr-Glu-Thr-Tyr) \\
F5-4 & 750.40 & YVPEPF (Tyr-Val-Pro-Glu-Pro-Phe) \\
\hline
\end{tabular}

\section{Structural Identification of Antioxidant Peptides}

Tandem MS is the most effective way of readily sequencing proteins and peptides (Biemann, 1992; Nemeth-Cawley et al., 2001). Structural identification of antioxidant peptides of F4-3, F4-5-1, F4-5-2, F5-2, and F5-4 derived from GMCH by using nano-electrospray ionization quadrupole-time-of-flight-tandem MS was conducted in this study, and their molecular weights and AA sequences are shown in Table 4 . These 5 oligopetides, Val-Tyr-Pro-Phe, Phe-Gly-Gly-Met-Ala-His, Phe-Pro-Tyr-Cys-Ala-Pro, Tyr-Val-Pro-Glu-Pro-Phe, and Tyr-Pro-Pro-Tyr-Glu-Thr-Tyr, had high antioxidant activity and might explain the high antioxidant activity of GMCH. The higher antioxidant activity of these 5 peptides could be explained by their AA composition and position. Hydrophobic AA have a significant scavenging effect on radicals. For peptides, a high content of hydrophobic AA could increase their antioxidant activity (Ren et al., 2008; Zhang et al., 2012). The first 4 antioxidant peptides were rich in hydrophobic AA residues, including Phe, Pro, Gly, and Ala, the content of which ranged from 66.67 to $83.33 \%$, and in Pro, Val, and Phe residues in the $\mathrm{N}$ - or C-terminal positions, and in His residues in the C-terminal position in the sequences, which enhanced their interactions with fatty acids and improved the capturing ability for lipid free radicals. This was in accordance with the results of Chen et al. (1998) and Qian et al. (2008). The fifth peptide, Tyr-Pro-Pro-Tyr-Glu-Thr-Tyr, had fewer hydrophobic AA residues, but its structure was very similar to the peptide Tyr-Gly-Asp-Glu-Tyr reported by Zhang et al. (2012), mainly in the existence of Tyr at the $\mathrm{C}$ - and $\mathrm{N}$-terminal positions. The antioxidant activity of Tyr might be due to the special capability of phenolic groups to serve as hydrogen donors, which is one mechanism of inhibiting the radical-mediated peroxidizing chain reaction (Sarmadi and Ismail, 2010). The sequences of the 5 antioxidant peptides cannot be retrieved in National Center for Biotechnology Information database and they differ from antioxidant peptides in milk and other foods reported by Pihlanto (2006) and Samaranayaka and Li-Chan (2011), respectively.

\section{CONCLUSIONS}

Goat milk casein was successfully hydrolyzed by a combination of neutral and alkaline protease. The antioxidant activity of GMCH was evaluated by 3 methods, and the antioxidant activity of GMCH was much higher than that of GMC. To understand the reason for the enhancement in antioxidant activity, GMCH was isolated, purified, and identified. Five novel peptides with higher antioxidant activity were obtained and their sequences were identified as Val-Tyr-Pro-Phe, Phe-Gly-Gly-MetAla-His, Phe-Pro-Tyr-Cys-Ala-Pro, Tyr-Val-Pro- GluPro-Phe, and Tyr-Pro-Pro-Tyr-Glu-Thr-Tyr. The work reported here is important for both basic research and application because it provides a new way to produce functional peptides for food ingredients, food additives, and pharmaceutical agents.

\section{ACKNOWLEDGMENTS}

We thank Ministry of Science and Technology (MOST), Government of PR China (No. 2012BAD12B07), Science and Technology Department of Shaanxi Province (No. 2011K01-04 and 2011KTCL02-11), and Northwest A\&F University (No. QN2011070) for their financial support. We also greatly thank Camus Adoligbe (College of Animal Science and Technology, Northwest A\&F University, Yangling, China) for the grammatical suggestions.

\section{REFERENCES}

Abuja, P. M., and R. Albertini. 2001. Methods for monitoring oxidative stress, lipid peroxidation and oxidation resistance of lipoproteins. Clin. Chim. Acta 306:1-17.

Aewsiri, T., S. Benjakul, W. Visessanguan, J. B. Eun, P. A. Wierenga, and H. Gruppen. 2009. Antioxidative activity and emulsifying properties of cuttlefish skin gelatin modified by oxidised phenolic compounds. Food Chem. 117:160-168.

Alférez, M. J. M., I. López-Aliaga, T. Nestares, J. Díaz-Castro, M. Barrionuevo, P. B. Ros, and M. S. Campos. 2006. Dietary goat milk improves iron bioavailability in rats with induced ferropenic anaemia in comparison with cow milk. Int. Dairy J. 16:813-821.

Biemann, K. 1992. Mass spectrometry of peptides and proteins. Annu. Rev. Biochem. 61:977-1010.

Bradford, M. M. 1976. A rapid and sensitive method for the quantitation of microgram quantities of protein utilizing the principle of protein-dye binding. Anal. Biochem. 72:248-254. 
Ceballos, L. S., E. R. Morales, G. D. T. Adarve, J. D. Castro, L. P. Martinez, and M. R. Sanz. 2009. Composition of goat and cow milk produced under similar conditions and analyzed by identical methodology. J. Food Compos. Anal. 22:322-329.

Chen, H. M., K. Muramoto, F. Yamauchi, K. Fujimoto, and K. Nokihara. 1998. Antioxidative properties of histidine-containing peptides designed from peptide fragments found in the digests of a soybean protein. J. Agric. Food Chem. 46:49-53.

Chen, H. M., K. Muramoto, F. Yamauchi, and K. Nokihara. 1996. Antioxidant activity of designed peptides based on the antioxidative peptide derived from digests of a soybean peptide. J. Agric. Food Chem. 44:2619-2623.

Chung, S. K., T. Osawa, and S. Kawakishi. 1997. Hydroxyl radical scavenging effects of spices and scavenging from Brown Mustard (Brassica nigra). Biosci. Biotechnol. Biochem. 61:118-123.

Collins, A. R. 2005. Antioxidant intervention as a route to cancer prevention. Eur. J. Cancer 41:1923-1930.

Guo, H., Y. Kouzuma, and M. Yonekura. 2009. Structures and properties of antioxidative peptides derived from royal jelly protein. Food Chem. 113:238-245.

Halliwell, B. 2000. Lipid peroxidation, antioxidants and cardiovascular disease: How should we move forward? Cardiovasc. Res. 47:410-418.

Halliwell, B., and J. M. C. Gutteridge. 1990. Role of free radicals and catalytic metal ions in human disease: An overview. Methods Enzymol. 186:1-85.

Halliwell, B., J. M. C. Gutteridge, and O. I. Aruoma. 1987. The deoxyribose method: A simple "test-tube" assay for determination of rate constants for reactions of hydroxyl radicals. Anal. Biochem. 165:215-219.

Hiller, B., and P. C. Lorenzen. 2009. Functional properties of milk proteins as affected by enzymatic oligomerisation. Food Res. Int. 42:899-908.

Hoelzl, C., J. Bichler, F. Ferk, T. Simic, A. K. Nersesyan, L. Elbling, V. A. Ehrlich, A. Chakraborty, and S. Knasmüller. 2005. Methods for the detection of antioxidants which prevent age related diseases: A critical review with particular emphasis on human intervention studies. J. Physiol. Pharmacol. 56:49-64.

Je, J. Y., Z. J. Qian, H. G. Byun, and S. K. Kim. 2007. Purification and characterization of an antioxidative peptide obtained from tuna backbone protein by enzymatic hydrolysis. Process Biochem. 42:840-846.

Kang, K. H., Z. J. Qian, B. M. Ryu, and S. K. Kim. 2011. Characterization of growth and protein contents from microalgae navicula incerta with the investigation of antioxidant activity of enzymatic Hydrolysates. Food Sci. Biotechnol. 20:183-191.

Kondyli, E., M. C. Katsiari, and L. P. Voutsinas. 2007. Amino acid composition and nutritional value of goat milk from the indigenous Greek breed. Milchwissenschaft 62:164-166.

Lee, K. J., S. B. Kim, J. S. Ryu, H. S. Shin, and J. W. Lim. 2005. Separation and purification of angiotensin converting enzyme inhibitory peptides derived from goat's milk casein hydrolysates. Asian australas. J. Anim. Sci. 18:741-746.

Li, B., F. Chen, X. Wang, B. Ji, and Y. Wu. 2007. Isolation and identification of antioxidant peptides from porcine collagen hydrolysate by consecutive chromatography and electrospray ionization-mass spectrometry. Food Chem. 102:1135-1143.

Mao, X. Y., X. Cheng, X. Wang, and S. J. Wu. 2011. Free-radicalscavenging and anti-inflammatory effect of yak milk casein before and after enzymatic hydrolysis. Food Chem. 126:484-490.

Nanjo, F., M. Mori, K. Goto, and Y. Hara. 1999. Radical scavenging activity of tea catechins and their related compounds. Biosci. Biotechnol. Biochem. 63:1621-1623.
Nemeth-Cawley, J. F., S. Kamik, and J. C. Rouse. 2001. Analysis of sulfated peptides using positive electrospray ionization tandem mass spectrometry. J. Mass Spectrom. 36:1301-1311.

Phelan, M., A. Aherne, R. J. FitzGerald, and N. M. O'Brien. 2009. Casein-derived bioactive peptides: Biological effects, industrial uses, safety aspects and regulatory status. Int. Dairy J. 19:643-654.

Pihlanto, A. 2006. Antioxidative peptides derived from milk proteins. Int. Dairy J. 16:1306-1314.

Qian, Z. J., W. K. Jung, and S. K. Kim. 2008. Free radical scavenging activity of a novel antioxidative peptide purified from hydrolysate of bullfrog skin, Rana catesbeiana Shaw. Bioresour. Technol. 99:1690-1698.

Rajapakse, N., E. Mendis, W. K. Jung, J. Y. Je, and S. K. Kim. 2005. Purification of a radical scavenging peptide from fermented mussel sauce and its antioxidative properties. Food Res. Int. 38:175-182.

Ren, J., M. Zhao, J. Shi, J. Wang, Y. Jiang, C. Cui, Y. Kakuda, and S. J. Xue. 2008. Purification and identification of antioxidant peptides from grass carp muscle hydrolysates by consecutive chromatography and electrospray ionization-mass spectrometry. Food Chem. 108:727-736.

Samaranayaka, A. G. P., and E. C. Y. Li-Chan. 2011. Food-derived peptidic antioxidants: A review of their production, assessment, and potential applications. J. Funct. Food 3:229-254.

Sarmadi, B. H., and A. Ismail. 2010. Antioxidative peptides from food proteins: A review. Peptides 31:1949-1956.

Siuzdak, G. 1994. The emergence of mass spectrometry in biochemical research. Proc. Natl. Acad. Sci. USA 91:11290-11297.

Sommerer, N., C. Salles, D. Promé, J. C. Promé, and J. L. Le Quéré. 2001. Isolation of oligopeptides from the water-soluble extract of goat cheese and their identification by mass spectrometry. J. Agric. Food Chem. 49:402-408.

Su, R., M. Liang, W. Qi, R. Liu, S. Yuan, and Z. He. 2012. Pancreatic hydrolysis of bovine casein: Peptide release and time-dependent reaction behavior. Food Chem. 133:851-858.

Suetsuna, K., H. Ukeda, and H. Ochi. 2000. Isolation and characterization of free radical scavenging activities peptides derived from casein. J. Nutr. Biochem. 11:128-131.

Thiansilakul, Y., S. Benjakul, and F. Shahidi. 2007. Antioxidative activity of protein hydrolysate from round scad muscle using alcalase and flavourzyme. J. Food Biochem. 31:266-287.

Tomotake, H., R. Okuyama, M. Katagiri, M. Fuzita, M. Yamato, and F. Ota. 2006. Comparison between Holstein cow's milk and Japanese-Saanen goat's milk in fatty acid composition, lipid digestibility and protein profile. Biosci. Biotechnol. Biochem. 70:2771-2774.

Urso, M. L., and P. M. Clarkson. 2003. Oxidative stress, exercise, and antioxidant supplementation. Toxicology 189:41-54.

Wang, D., L. J. Wang, F. X. Zhu, J. Y. Zhu, X. D. Chen, L. Zou, M. Saito, and L. T. Li. 2008. In vitro and in vivo studies on the antioxidant activities of the aqueous extracts of Douchi. Food Chem. 107:1421-1428.

Xie, Z., J. Huang, and X. Xu. 2008. Antioxidant activity of peptides isolated from alfalfa leaf protein hydrolysate. Food Chem. 111:370-376

Yokozawa, T., C. P. Chen, E. Dong, T. Tanaka, G. I. Nonaka, and I. Nishioka. 1998. Study on the inhibitory effect of tannins and flavonoids against the 1,1- diphenyl-2-picrylhydrazyl radical. Biochem. Pharmacol. 56:213-222.

Zhang, Y., X. Duan, and Y. Zhuang. 2012. Purification and characterization of novel antioxidant peptides from enzymatic hydrolysates of tilapia (Oreochromis niloticus) skin gelatin. Peptides 38:13-21.

Zhu, K., H. Zhou, and H. Qian. 2006. Antioxidant and free radicalscavenging activities of wheat germ protein hydrolysates (WGPH) prepared with alcalase. Process Biochem. 41:1296-1302. 